\title{
Assessing the differences in characteristics of patients lost to follow-up at 2 years: results from the Quality Outcomes Database study on outcomes of surgery for grade I spondylolisthesis
}

\author{
Erica F. Bisson, MD, MPH, ${ }^{1}$ Praveen V. Mummaneni, MD, ${ }^{2}$ John Knightly, MD, ${ }^{3}$ \\ Mohammed Ali Alvi, MBBS, ${ }^{4}$ Anshit Goyal, MBBS, ${ }^{4}$ Andrew K. Chan, MD, Jian Guan, MD, ${ }^{1}$ \\ Michael Biase, ${ }^{3}$ Andrea Strauss, ${ }^{1}$ Steven Glassman, MD, ${ }^{5}$ Kevin Foley, MD, ${ }^{6}$ \\ Jonathan R. Slotkin, MD, ${ }^{7}$ Eric Potts, MD, ${ }^{8}$ Mark Shaffrey, MD, ${ }^{9}$ Christopher I. Shaffrey, MD, ${ }^{10,11}$ \\ Regis W. Haid Jr., MD, ${ }^{3}$ Kai-Ming Fu, MD, ${ }^{12}$ Michael Y. Wang, MD, ${ }^{13}$ Paul Park, MD, ${ }^{14}$ \\ Anthony L. Asher, MD, ${ }^{15}$ and Mohamad Bydon, MD4 \\ 1Department of Neurological Surgery, University of Utah, Salt Lake City, Utah; ${ }^{2}$ Department of Neurological Surgery, University \\ of California, San Francisco, California; ${ }^{3}$ Atlantic Neurosurgical Specialists, Morristown, New Jersey; ${ }^{4}$ Department of Neurologic \\ Surgery, Mayo Clinic, Rochester, Minnesota; ${ }^{5}$ Norton Leatherman Spine Center, Louisville, Kentucky; ${ }^{6}$ Department of \\ Neurosurgery, University of Tennessee, Memphis, Tennessee; ${ }^{7}$ Geisinger Health System, Danville, Pennsylvania; ${ }^{8}$ Department \\ of Neurological Surgery, Goodman Campbell Brain and Spine, Indianapolis, Indiana; 'Department of Neurological Surgery, \\ University of Virginia Health System, Charlottesville, Virginia; Departments of ${ }^{10}$ Neurological Surgery and ${ }^{11}$ Orthopedic Surgery, \\ Duke University, Durham, North Carolina; ${ }^{2}$ Department of Neurological Surgery, Weill Cornell Medical College, New York, \\ New York; ${ }^{13}$ Department of Neurologic Surgery, University of Miami, Florida; ${ }^{14}$ Department of Neurologic Surgery, University of \\ Michigan, Ann Arbor, Michigan; and ${ }^{15}$ Neuroscience Institute, Carolinas Healthcare System and Carolina Neurosurgery \& Spine \\ Associates, Charlotte, North Carolina
}

OBJECTIVE Loss to follow-up has been shown to bias outcomes assessment among studies utilizing clinical registries. Here, the authors analyzed patients enrolled in a national surgical registry and compared the baseline characteristics of patients captured with those lost to follow-up at 2 years.

METHODS The authors queried the Quality Outcomes Database for patients with grade I lumbar degenerative spondyIolisthesis undergoing a surgical intervention between July 2014 and June 2016. Only those patients enrolled in a multisite study investigating the impact of fusion on clinical and patient-reported outcomes (PROs) among patients with grade I spondylolisthesis were evaluated.

RESULTS Of the 608 patients enrolled in the study undergoing 1- or 2-level decompression $(23.0 \%, n=140)$ or 1-level fusion $(77.0 \%, n=468), 14.5 \%(n=88)$ were lost to follow-up at 2 years. Patients who were lost to follow-up were more likely to be younger ( $59.6 \pm 13.5$ vs $62.6 \pm 11.7$ years, $p=0.031$ ), be employed (unemployment rate: $53.3 \%$ [ $n=277]$ for successful follow-up vs $40.9 \%$ [ $n=36$ ] for those lost to follow-up, $p=0.017)$, have anxiety $(26.1 \%$ [ $n=23$ ] vs $16.3 \%$ [n = 85 ], $p=0.026)$, have higher back pain scores $(7.4 \pm 2.9$ vs $6.6 \pm 2.8, p=0.010)$, have higher leg pain scores $(7.4 \pm 2.5$ vs $6.4 \pm 2.9, p=0.003$ ), have higher Oswestry Disability Index scores ( $50.8 \pm 18.7$ vs $46 \pm 16.8, p=0.018$ ), and have lower EQ-5D scores $(0.481 \pm 0.2$ vs $0.547 \pm 0.2, p=0.012)$ at baseline.

CONCLUSIONS To execute future, high-quality studies, it is important to identify patients undergoing surgery for spondylolisthesis who might be lost to follow-up. In a large, prospective registry, the authors found that those lost to follow-up were more likely to be younger, be employed, have anxiety disorder, and have worse PRO scores.

https://thejns.org/doi/abs/10.3171/2019.12.SPINE191155

KEYWORDS follow-up; spondylolisthesis; Quality Outcomes Database; QOD; spine surgery; lumbar; registry; database 
$\mathrm{T}$ HE Affordable Care Act of 2010 introduced some important legislation in order to curb increasing healthcare costs. ${ }^{7}$ This legislation was primarily focused around promoting a more value-based care model of healthcare, which equates value to the quality of care delivered divided by the cost incurred. ${ }^{6}$ An important aspect of this effort was to encourage physicians, hospitals, and other stakeholders of healthcare to engage in critical research on quality and cost-effectiveness of treatment. ${ }^{23}$ However, defining the quality in healthcare is challenging, and the resources and infrastructure for assessing it are not often available. ${ }^{3}$ To address this shortcoming, clinical registries have been heralded as a plausible platform to define, assess, and promote quality in healthcare. ${ }^{3}$

One of the key challenges in clinical registries is loss to follow-up or attrition, where a patient, after being enrolled in a study, has to be excluded from the final analysis due to missing outcomes assessments. ${ }^{12}$ Loss to follow-up has been shown to bias the outcomes assessment of patients as well as reduce statistical power. ${ }^{16-20,29,30}$ Moreover, previous studies have shown that patients who are lost to follow-up in clinical trials may have worse outcomes than those who successfully complete follow-up. ${ }^{27,31}$ However, not much is known about the characteristics of patients enrolled in surgical registries who are lost to follow-up and how they differ from patients who successfully complete follow-up.

Herein, we analyzed patients with Meyerding grade I lumbar spondylolisthesis who underwent a surgical intervention and were enrolled in a clinical registry, and we compared the characteristics of patients lost to follow-up at 2 years with those who successfully underwent follow-up.

\section{Methods \\ Cohort}

For this study, the Quality Outcomes Database (QOD), formerly known as the National Neurosurgical Quality and Outcomes Database $\left(\mathrm{N}^{2} \mathrm{QOD}\right)$, was queried for patients undergoing surgery for Meyerding grade I degenerative lumbar spondylolisthesis between July 1, 2014, and June 30, 2016. The QOD is a prospective multiinstitutional registry, established in 2012 with the objective of assessing risk-adjusted expected morbidity and 30-day and 12-month patient-reported outcomes (PROs) and clinical outcomes in order to establish a data-driven mechanism of providing insight into improving quality of care for routinely performed spine surgeries in the United States. ${ }^{19,25}$ As of February 2019, more than 78,879 patients undergoing any lumbar surgery for degenerative disease across 105 participating sites throughout the nation have been enrolled in the lumbar spine surgery QOD module. ${ }^{28}$ Among these sites, the 12 highest-enrolling sites that were enrolling patients into the lumbar spine module came together to initiate a focused project to assess the impact of fusion on PROs in patients undergoing surgery for grade I lumbar spondylolisthesis. ${ }^{1,8,9,10,26}$ In order to determine the diagnosis of grade I spondylolisthesis, surgeons at each of the participating sites evaluated preoperative standing or dynamic radiographs..$^{1,8,9,10,26}$ The primary outcome of in- terest for this study was Oswestry Disability Index (ODI). Informed consent and institutional review board approval from the University of Utah were obtained.

\section{Outcome of Interest}

For the current study, the outcome of interest was the status of follow-up at 2 years, based on the availability of ODI data, the primary outcome of interest, and patients were categorized as either lost to follow-up or successfully captured.

\section{Variables Compared}

The following variables were included in the analyses for the current study:1,8,9,10,26 1) demographic characteristics, including age, sex, BMI, ethnicity, insurance, education level, employment, and workers' compensation; 2) comorbidities, including smoking, diabetes, anxiety, osteoporosis, depression, and American Society of Anesthesiologists (ASA) classification; 3) clinical characteristics, such as symptom duration, dominant symptom, ambulation, and presence of motor deficit; and 4) baseline PROs, including ODI, ${ }^{14} \mathrm{EQ}-5 \mathrm{D},{ }^{13}$ and numeric rating scale (NRS) for back and leg pain. ${ }^{21}$ Other surgical variables, such as intraoperative blood loss, operative time, interbody graft, and use of minimally invasive techniques, were also documented. A case was regarded as a minimally invasive procedure if there was documentation of utilization of percutaneous or tubular screw fixation or tubular laminectomy with or without intervertebral body graft placement.

\section{Statistical Analysis}

Continuous variables are summarized using means with SD, and categorical variables are summarized using frequencies with proportions. We also performed a multivariable analysis to predict loss to follow-up at 2 years after adjusting for a multitude of demographic, clinical, and comorbid characteristics and baseline PROs. All analyses were performed using the rms and Arsenal packages (https://cran.r-project.org/web/packages/arsenal) in $\mathrm{R}$ (version 3.3.1, R Foundation for Statistical Computing, www.R-project.org); p values were two-tailed and were considered significant at $<0.05$.

\section{Results}

\section{Patient Population and Follow-Up}

A total of 608 patients across the 12 sites underwent surgical intervention for grade I spondylolisthesis. Of these, $141(23.0 \%)$ underwent 1- or 2-level decompression alone, whereas 467 (77.0\%) underwent 1-level decompression and fusion. At the 2-year follow-up, a total of 88 patients $(14.5 \%)$ were lost to follow-up, while the remaining 520 patients $(85.5 \%)$ were successfully followed up.

\section{Demographic Characteristics}

Patients who were lost to follow-up were slightly younger than those who were successfully followed up $(59.6 \pm 13.5$ vs $62.6 \pm 11.7$ years, $\mathrm{p}=0.031)$. Compared with patients who were successfully followed up, patients who were lost to follow-up were more likely to be em- 
TABLE 1. Analysis of demographic characteristics between patients who were lost to follow-up and those who were successfully followed up

\begin{tabular}{|c|c|c|c|c|}
\hline & Total & Lost to Follow-Up & Successfully Followed Up & $\mathrm{p}$ Value \\
\hline No. of patients (\%) & 608 & $88(14.5)$ & $520(85.5)$ & \\
\hline Age in yrs, mean (SD) & $62.2(12.1)$ & $59.6(13.5)$ & $62.6(11.7)$ & 0.031 \\
\hline Sex, n (\%) & & & & 0.277 \\
\hline Female & $350(57.6)$ & $46(52.3)$ & $304(58.5)$ & \\
\hline Male & $258(42.4)$ & $42(47.7)$ & $216(41.5)$ & \\
\hline Insurance, n (\%) & & & & 0.722 \\
\hline Medicaid & $36(5.9)$ & $6(6.8)$ & $30(5.8)$ & \\
\hline Medicare & $235(38.7)$ & $30(34.1)$ & $205(39.4)$ & \\
\hline Private & $319(52.5)$ & $48(54.5)$ & $271(52.1)$ & \\
\hline Uninsured & $1(0.2)$ & $0(0.0)$ & $1(0.2)$ & \\
\hline VA/government & $17(2.8)$ & $4(4.5)$ & $13(2.5)$ & \\
\hline Workers' compensation, n (\%) & $27(4.4)$ & $5(5.7)$ & $22(4.2)$ & 0.533 \\
\hline BMI, mean (SD) & $30.4(6.4)$ & $31.6(5.9)$ & $30.2(6.4)$ & 0.068 \\
\hline Ethnicity, n (\%) & & & & 0.427 \\
\hline Hispanic & $29(4.8)$ & $6(6.8)$ & $23(4.4)$ & \\
\hline Non-Hispanic & $560(92.1)$ & $78(88.6)$ & $482(92.7)$ & \\
\hline Prefer not to answer & $19(3.1)$ & $4(4.5)$ & $15(2.9)$ & \\
\hline Education, n (\%) & & & & 0.564 \\
\hline 4-yr college degree & $121(19.9)$ & $17(19.3)$ & $104(20.0)$ & \\
\hline High school & $238(39.1)$ & $39(44.3)$ & 199 (38.3) & \\
\hline Less than high school & $17(2.8)$ & $1(1.1)$ & $16(3.1)$ & \\
\hline Post-college & $108(17.8)$ & $10(11.4)$ & $98(18.8)$ & \\
\hline Prefer not to answer & $10(1.6)$ & $2(2.3)$ & $8(1.5)$ & \\
\hline 2-yr college degree & $109(17.9)$ & $18(20.5)$ & $91(17.5)$ & \\
\hline Employment, n (\%) & & & & 0.017 \\
\hline Employed \& working & $244(40.1)$ & $41(46.6)$ & $203(39.0)$ & \\
\hline Employed but not working* & $31(5.1)$ & $4(4.5)$ & $27(5.2)$ & \\
\hline Unemployed & $313(51.5)$ & $36(40.9)$ & $277(53.3)$ & \\
\hline
\end{tabular}

ployed (unemployment rate: $53.3 \%$ [ $n=277]$ for those with successful follow-up vs $40.9 \%$ [ $=36$ ] for those lost to follow-up, $p=0.017$ overall). The 2 groups did not differ in distribution of sex $(\mathrm{p}=0.277)$, insurance status $(\mathrm{p}=$ $0.722)$, BMI $(p=0.068)$, ethnicity $(p=0.427)$, and education status $(p=0.564)$. These characteristics are presented in Table 1.

\section{Comorbidity Status and Clinical Characteristics}

Compared with patients who were successfully followed up, those lost to follow-up were more likely to have an anxiety disorder $(26.1 \%$ [ $\mathrm{n}=23]$ vs $16.3 \%$ [ $\mathrm{n}=85]$, $\mathrm{p}=0.026)$. We did not find any difference between the two groups in distribution of those on workers' compensation $(\mathrm{p}=0.533)$, those with a history of major surgery in the past $(\mathrm{p}=0.5)$, smoking status $(\mathrm{p}=0.179)$, diabetes $(0.848)$, coronary artery disease $(\mathrm{p}=0.954)$, depression ( $\mathrm{p}$ $=0.136)$, osteoporosis $(\mathrm{p}=0.812)$, dominant symptom $(\mathrm{p}=$
0.116), motor deficit at the time of presentation $(\mathrm{p}=0.808)$, ambulation status $(\mathrm{p}=0.090)$, and symptom duration $(\mathrm{p}=$ 0.376). These results are summarized in Table 2 .

\section{Operative Characteristics}

The proportion of patients undergoing laminectomy alone and laminectomy and fusion was found to be similar between the two groups (laminectomy and fusion: 75\% [ $\mathrm{n}=66$ ] in those lost to follow-up vs $77.3 \%$ [ $\mathrm{n}=402$ ], $\mathrm{p}=$ 0.634). Moreover, we did not find any difference between the two groups in terms of ASA class $(p=0.626)$, surgical approach $(\mathrm{p}=0.053)$, proportion of patients undergoing minimally invasive decompression $(\mathrm{p}=0.758)$, proportion of patients undergoing minimally invasive fusion ( $\mathrm{p}$ $=0.260)$, estimated blood loss $(p=0.212)$, length of surgery $(p=0.280)$, length of stay $(p=0.333)$, or discharge disposition $(\mathrm{p}=0.501)$. These results are summarized in Table 3. 
TABLE 2. Analysis of comorbid status and clinical characteristics between patients who were lost to follow-up and those who were successfully followed up

\begin{tabular}{lcccc}
\hline & Total & Lost to Follow-Up & Successfully Followed Up & p Value \\
\hline & 608 & 88 & 520 & \\
\hline Any major surgery in the past & $70(11.5)$ & $12(13.6)$ & $58(11.2)$ & 0.500 \\
\hline Smoking status & $71(11.8)$ & $14(16.1)$ & $57(11.1)$ & 0.179 \\
\hline Diabetes & $101(16.6)$ & $14(15.9)$ & $87(16.7)$ & 0.848 \\
\hline CAD & $68(11.2)$ & $10(11.4)$ & $58(11.2)$ & 0.954 \\
\hline Anxiety & $108(17.8)$ & $23(26.1)$ & $85(16.3)$ & 0.026 \\
\hline Depression & $123(20.2)$ & $23(26.1)$ & $100(19.2)$ & 0.136 \\
\hline Osteoporosis & $38(6.2)$ & $6(6.8)$ & $32(6.2)$ & 0.812 \\
\hline Dominant symptom & & & & 0.116 \\
\hline Back dominant & $230(37.8)$ & $35(39.8)$ & $195(37.5)$ & \\
\hline Leg dominant & $131(21.5)$ & $25(28.4)$ & $106(20.4)$ & \\
\hline Leg equals back & $247(40.6)$ & $28(31.8)$ & $219(42.1)$ & \\
\hline Motor deficit & $139(22.9)$ & $22(25.0)$ & $117(22.5)$ & 0.808 \\
\hline Ambulation & & & & 0.090 \\
\hline Independent & $537(88.3)$ & $73(83.0)$ & $464(89.2)$ & \\
\hline Not independent & $71(11.7)$ & $15(17.0)$ & $56(10.8)$ & \\
\hline Symptom duration & & & & \\
\hline$>3$ mos & $571(93.9)$ & $82(93.2)$ & $14(2.7)$ & \\
\hline$<3$ mos & $15(2.5)$ & $1(1.1)$ & & \\
\hline
\end{tabular}

$\mathrm{CAD}=$ coronary artery disease.

Values are presented as number of patients (\%). Boldface type indicates statistical significance.

TABLE 3. Analysis of operative characteristics between patients who were lost to follow-up and those who were successfully followed up

\begin{tabular}{|c|c|c|c|c|}
\hline & Total $(n=608)$ & Lost to Follow-Up $(n=88)$ & Successfully Followed Up $(n=520)$ & $p$ Value \\
\hline ASA class, $n(\%)$ & & & & 0.626 \\
\hline | or II & $346(56.9)$ & $47(53.4)$ & $299(57.5)$ & \\
\hline III or IV & $237(39.0)$ & $36(40.9)$ & $201(38.7)$ & \\
\hline Surgical approach, n (\%) & & & & 0.053 \\
\hline Anterior only & $17(2.8)$ & $3(3.4)$ & $14(2.7)$ & \\
\hline Lateral only & $7(1.2)$ & $0(0.0)$ & $7(1.3)$ & \\
\hline Posterior only & $559(91.9)$ & $83(94.3)$ & $476(91.5)$ & \\
\hline 2-stage & $24(3.9)$ & $1(1.1)$ & $23(4.4)$ & \\
\hline Group, n (\%) & & & & 0.634 \\
\hline Laminectomy alone & $140(23.0)$ & $22(25.0)$ & $118(22.7)$ & \\
\hline Laminectomy \& fusion & $468(77.0)$ & $66(75.0)$ & $402(77.3)$ & \\
\hline MIS decompression, $\mathrm{n}(\%)$ & $226(37.2)$ & $34(38.6)$ & $192(36.9)$ & 0.758 \\
\hline MIS fusion, $\mathrm{n}(\%)$ & $157(25.8)$ & $27(30.7)$ & $130(25.0)$ & 0.260 \\
\hline Estimated blood loss, mean (SD) & $185.9(200.6)$ & $161.2(168.5)$ & $190.3(205.4)$ & 0.212 \\
\hline Length of surgery, mean (SD) & $176.2(85.6)$ & $167.1(86.1)$ & $177.8(85.5)$ & 0.280 \\
\hline Length of stay, mean (SD) & $2.7(1.8)$ & $2.6(1.8)$ & $2.7(1.8)$ & 0.333 \\
\hline Discharge disposition, $\mathrm{n}(\%)$ & & & & 0.501 \\
\hline Home & $516(84.9)$ & $72(81.8)$ & $444(85.4)$ & \\
\hline Not home & $89(14.6)$ & $15(17.0)$ & $74(14.2)$ & \\
\hline
\end{tabular}

MIS = minimally invasive surgery. 


\section{Patient-Reported Outcomes}

Compared with patients who were successfully followed up, those lost to follow-up were more likely to have higher back pain NRS scores $(7.4 \pm 2.9$ vs $6.6 \pm 2.8$, p = $0.010)$, higher leg pain NRS scores $(7.4 \pm 2.5$ vs $6.4 \pm 2.9$, $\mathrm{p}=0.003)$, higher ODI scores $(50.8 \pm 18.7$ vs $46 \pm 16.8, \mathrm{p}$ $=0.018)$, and lower EQ-5D scores $(0.481 \pm 0.2$ vs $0.547 \pm$ $0.2, \mathrm{p}=0.012)$ at baseline

We also evaluated the 3-month and 12-month outcomes of these patients. Of those who were lost to follow-up at 2 years, $80.7 \%(\mathrm{n}=71)$ had 3 -month outcomes, while among those who were captured successfully at 2 years, $88.7 \%$ $(\mathrm{n}=461)$ had available 3-month outcomes. Patients who were lost to follow-up had a significantly greater change in 3-month EQ-5D scores $(0.329 \pm 0.317$ vs $0.220 \pm 0.293$, $\mathrm{p}=0.005$ ). We observed no difference in 3-month ODI scores, change in 3-month ODI scores, 3-month NRS back pain scores, change in 3-month NRS back pain scores, 3-month NRS leg pain scores, change in 3-month NRS leg pain scores, 3-month EQ-5D scores, North American Spine Society (NASS) patient satisfaction at 3 months, and return to work at 3 months. We also observed no difference between the two groups for back pain, leg pain, ODI score, EQ-5D, and patient satisfaction at 12 months. These results are summarized in Table 4.

\section{Multivariable Analysis to Predict Loss to Follow-Up at 2 Years}

A multivariable logistic regression analysis was fit to identify factors associated with loss to follow-up at 2 years. We found that active employment, compared with unemployment, was associated with lower odds of being successfully captured at 2 years (OR $0.48,95 \%$ CI $0.23-$ $0.99 ; \mathrm{p}=0.038)$ (Fig. 1).

\section{Discussion}

In the current study of patients with Meyerding grade I spondylolisthesis undergoing surgical management, we found that $88(14.5 \%)$ were lost to follow-up at 2 years. Moreover, we found that patients lost to follow-up at 2 years were more likely to be younger, be employed, have an anxiety disorder, and have worse scores on PRO measures at baseline.

Loss to follow-up poses a threat to the validity of the results in prospective studies. ${ }^{12}$ Experts in evidence-based medicine have stated that a loss to follow-up rate of greater than $20 \%$ may significantly bias the results. ${ }^{24}$ In our cohort, $14.5 \%$ patients were lost to follow-up, thus increasing the confidence in our overall results and preventing significant bias to be introduced in the study. Moreover, even without a significantly higher proportion of patients who were lost to follow-up, a differential loss to follow-up may still bias outcomes. In most cases, differential loss to follow-up is said to occur if patients in one of the groups stratified by the primary predictor of interest may be at a higher "differential" risk of loss to follow-up. In our cohort, we found that those who were lost to follow-up did not differ significantly in terms of our primary predictor of interest, i.e., the proportion of patients undergoing laminectomy alone versus laminectomy and fusion.
We found that demographic characteristics may be associated with a higher likelihood of patients being lost to follow-up. In our cohort, those lost to follow-up were more likely to be younger and employed at the time of surgery. These results agree with those presented by Solberg et al. in their experience with the Norwegian Registry for Spine Surgery (NORspine), who found that patients who did not return for follow-up or return a postal questionnaire were more likely to be younger and also more likely to be working full time at the time of surgery. ${ }^{32}$ It is important to highlight that even patients on Medicaid were successfully followed up to 2 years (30/36 or 83.3\%). This subset of patients has been shown to be at a higher risk of being lost to follow-up in previous studies. ${ }^{11}$ Successful followup of such patients speaks to the value of having a strong infrastructure in the form of a national registry, which may guide future prospective multiinstitutional research studies.

We also found that patients with anxiety disorder were more likely to be lost to follow-up. Bair et al. followed 3623 patients for 2.8 years who presented with pain due to a temporomandibular disorder in the Orofacial Pain: Prospective Evaluation and Risk Assessment (OPPERA) study and found that patients who were lost to follow-up (16\%) were more likely to perform poorly on the baseline psychological questionnaire..$^{5}$ On the other hand, Solberg et al. in the NORspine study found no difference between the two groups in terms of anxiety and/or depression..$^{32}$

In terms of PROs, we found that patients lost to follow-up were more likely to have higher back pain scores, higher leg pain scores, and worse ODI and EQ-5D scores than those who were successfully followed up. While these results may indicate a relatively more severe state of disease and poorer quality of life at baseline, previous studies have shown that PRO scores at baseline may not be significantly associated with long-term outcomes. ${ }^{4} \mathrm{We}$ also found that patients who were lost to follow-up had significantly greater improvement in their quality of life at 3 months, as evident by the greater change in EQ-5D scores at 3 months, compared with those who were successfully followed up. This finding, along with younger age and active employment among those who were lost to follow-up in our cohort, may be indicative of the fact that younger patients with more physiological reserve and capacity to improve may be at risk of being lost to followup and should thus be counseled appropriately preoperatively regarding the importance of following up with the provider team. This should involve a discussion regarding how this follow-up information may help the community at large by guiding physicians and other stakeholders to identify effective care treatments and rethink less effective ones.

Finally, a discussion regarding preventing and mitigating loss to follow-up in such clinical registries is also warranted. Some of the most crucial aspects of starting and maintaining a clinical registry are to have a clear definition of the target population and the availability of resources at each participating institution. ${ }^{15}$ Moreover, Klaiman et al. identified 6 key characteristics for maintaining a successful clinical registry; one of these is "accuracy/completeness of data," for which other authors have stated, 
TABLE 4. Analysis of PROs at baseline and at 3 and 12 months between patients who were lost to follow-up and those who were successfully followed up

\begin{tabular}{|c|c|c|c|c|}
\hline & Total $(n=608)$ & Lost to Follow-Up $(n=88)$ & Successfully Followed Up $(n=520)$ & $\mathrm{p}$ Value \\
\hline & \multicolumn{4}{|c|}{ Baseline Measures } \\
\hline ODI, mean (SD) & $46.7(17.2)$ & $50.8(18.7)$ & $46(16.8)$ & 0.018 \\
\hline NRS back pain, mean (SD) & $6.7(2.8)$ & $7.4(2.9)$ & $6.6(2.8)$ & 0.010 \\
\hline NRS leg pain, mean (SD) & $6.6(2.8)$ & $7.4(2.5)$ & $6.4(2.9)$ & 0.003 \\
\hline \multirow[t]{2}{*}{ EQ-5D, mean (SD) } & $0.537(0.2)$ & $0.481(0.2)$ & $0.547(0.2)$ & 0.012 \\
\hline & \multicolumn{4}{|c|}{ 3-Mo Outcomes } \\
\hline ODI, mean (SD) & $26.357(19.324)$ & $26.746(19.253)$ & $26.297(19.355)$ & 0.855 \\
\hline Change in ODI, mean (SD) & $26.357(19.324)$ & $24.942(29.892)$ & $19.563(26.367)$ & 0.121 \\
\hline NRS back pain, mean (SD) & $20.268(26.886)$ & $24.942(29.892)$ & $19.563(26.367)$ & 0.588 \\
\hline Change in NRS back pain, mean (SD) & $3.071(2.644)$ & $3.232(2.635)$ & $3.047(2.648)$ & 0.356 \\
\hline NRS leg pain, mean (SD) & $3.528(3.722)$ & 3.935 (3.991) & $3.468(3.682)$ & 0.691 \\
\hline Change in NRS leg pain, mean (SD) & $2.278(2.866)$ & $2.406(2.820)$ & $2.259(2.876)$ & 0.095 \\
\hline EQ-5D, mean (SD) & $0.760(0.192)$ & $0.770(0.179)$ & $0.759(0.194)$ & 0.645 \\
\hline Change in EQ-5D score, mean (SD) & $0.235(0.298)$ & $0.329(0.317)$ & $0.220(0.293)$ & 0.005 \\
\hline NASS satisfaction, $\mathrm{n}(\%)$ & & & & 0.067 \\
\hline 1 & $383(72.1)$ & $44(63.8)$ & $339(73.4)$ & \\
\hline 2 & $90(16.9)$ & $18(26.1)$ & $72(15.6)$ & \\
\hline 3 & $25(4.7)$ & $5(7.2)$ & $20(4.3)$ & \\
\hline 4 & $33(6.2)$ & $2(2.9)$ & $31(6.7)$ & \\
\hline \multirow[t]{2}{*}{$\begin{array}{l}\text { Return to work (among preoperatively } \\
\text { employed), } n(\%)\end{array}$} & $81 / 275(29.5)$ & $12 / 45(26.7)$ & $69(30.0)$ & \\
\hline & \multicolumn{4}{|c|}{ 12-Mo Outcomes } \\
\hline ODI, mean (SD) & $22.072(19.868)$ & $25.442(22.831)$ & $21.726(19.537)$ & 0.238 \\
\hline Change in ODI, mean (SD) & $24.338(19.601)$ & $25.445(22.209)$ & $24.225(19.339)$ & 0.695 \\
\hline NRS back pain, mean (SD) & $2.880(2.723)$ & $3.375(2.924)$ & $2.833(2.703)$ & 0.229 \\
\hline Change in NRS back pain, mean (SD) & $3.800(3.181)$ & $4.086(3.320)$ & $3.773(3.171)$ & 0.578 \\
\hline NRS leg pain, mean (SD) & $2.332(2.978)$ & $2.625(3.184)$ & $2.304(2.960)$ & 0.515 \\
\hline Change in NRS leg pain, mean (SD) & $2.332(2.978)$ & $2.625(3.184)$ & $2.304(2.960)$ & 0.515 \\
\hline EQ-5D score, mean (SD) & $0.775(0.205)$ & $0.760(0.219)$ & $0.776(0.203)$ & 0.631 \\
\hline Change in EQ-5D score, mean (SD) & $-0.230(0.242)$ & $0.266(0.262)$ & $0.227(0.240)$ & 0.302 \\
\hline NASS satisfaction, $\mathrm{n}(\%)$ & & & & 0.340 \\
\hline 1 & $306(66.2)$ & $24(58.5)$ & $282(67.0)$ & \\
\hline 2 & $87(18.8)$ & $11(26.8)$ & $76(18.1)$ & \\
\hline 3 & $39(8.4)$ & $2(4.9)$ & $37(8.8)$ & \\
\hline 4 & $30(6.5)$ & $4(9.8)$ & $26(6.2)$ & \\
\hline
\end{tabular}

Boldface type indicates statistical significance.

"robust methods need to be in place in order to minimize the amount of missing data and support meticulous followup efforts, particularly for patients who travel out of state for further evaluation or treatment." ${ }^{20}$ In that regard, the QOD has a well-defined plan for each of its participating members. For enrolling and following patients, all data extractors and site coordinators are required to undergo extensive training on data entry and standard operating procedures that have been outlined in the QOD infrastructure..$^{2,19}$ The first 6 patients who are found to satisfy the prespecified eligibility criteria are identified from the weekly posted surgical schedule. After that, these patients are then contacted either in person at a clinic or by phone and the health status is assessed using an established framework. Each of the participating sites is informed weekly of missing data. In addition, periodic surgeon-led self-audits of data as well as random audits are performed to ensure data completeness and accuracy. ${ }^{3}$ These checks and balances are necessary to maintain the integrity of the data as well as minimizing loss to follow-up of patients who are included. Ultimately, the most critical role of such registries is to curb healthcare costs, by identifying effective care protocols and eliminating cost-intensive practices. For instance, Larsson et al. studied 13 registries from 5 countries, in- 


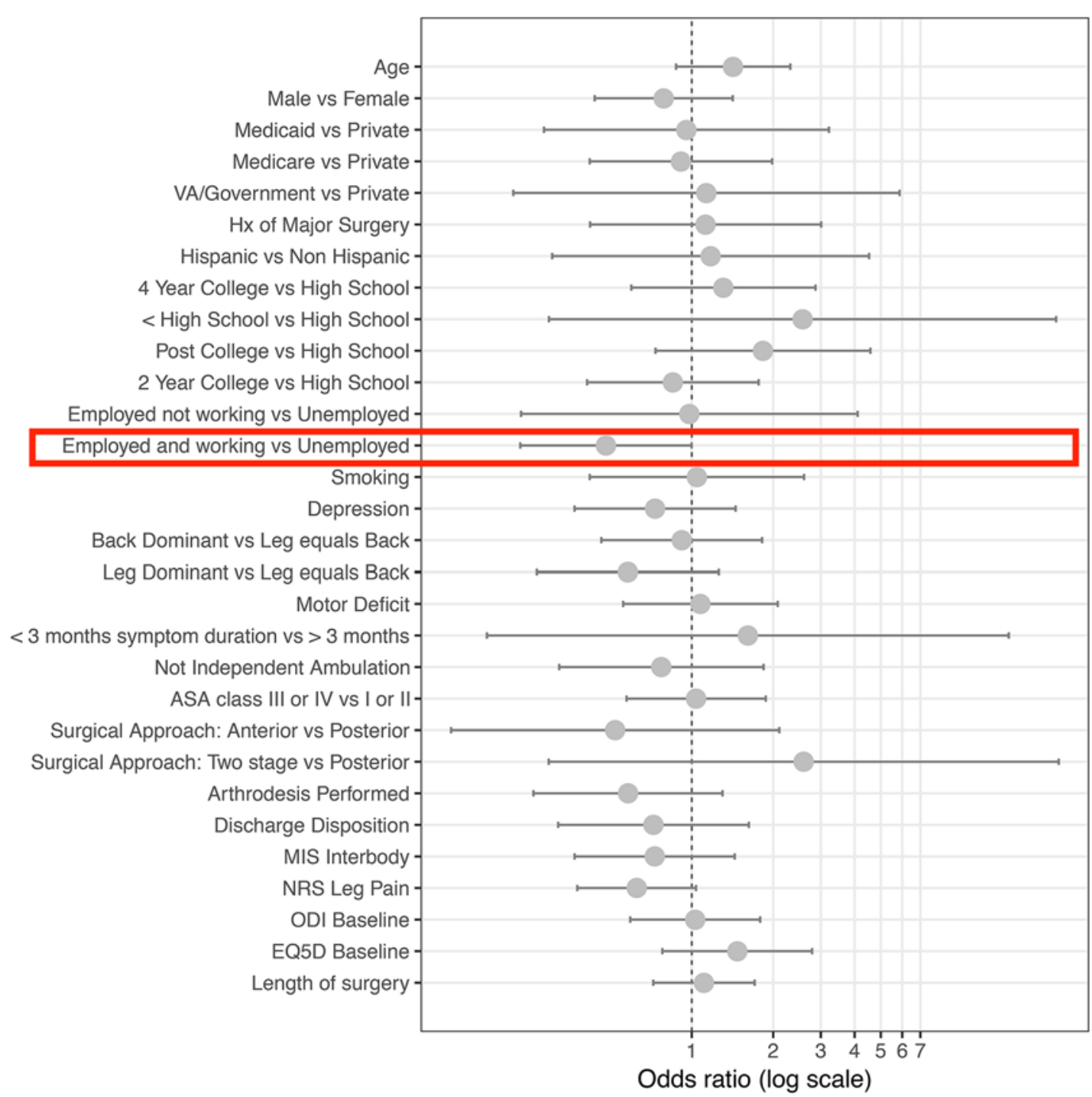

FIG. 1. Multivariable model to identify factors associated with loss to follow-up at 2 years. $\mathrm{Hx}=$ history; MIS = minimally invasive surgery. Figure is available in color online only.

cluding the US, and suggested that by making outcomes data available and transparent to the public and providers, well-maintained registries may provide an opportunity to healthcare providers to engage in active learning and adapt evidence-based best clinical practices. ${ }^{22}$

\section{Limitations}

Our study may have some limitations. Due to its multiinstitutional design, there may be some unknown regionspecific or site-specific factors that play a role in patients being lost to follow-up. Also, patients from 12 sites participating in the QOD were included in the current study. We acknowledge that there are numerous other sites in the QOD, and the generalizability of our findings reported here remains to be assessed. Moreover, it is crucial not only to investigate reasons why patients are lost to followup, but also to make an effort to investigate the longer-term outcomes of those who are lost to follow-up. Finally, we acknowledge that study coordinators have an important role in ensuring follow-up for a registry, and factors pertaining to time commitment for coordinators and contact protocols may also have an impact on follow-up. Nevertheless, our study is one of the largest to date that has investigated the characteristics at baseline among patients who are lost to follow-up. Further investigation is required to validate our findings for other diagnoses and other spinal procedures.

\section{Conclusions}

In order to execute better-designed studies in the future, it is important to investigate the characteristics of patients who may be lost to follow-up in the long term. In this study of patients with Meyerding grade I spondylolisthesis undergoing surgical intervention and enrolled in a national clinical registry, we found that patients who were lost to follow-up at 2 years were more likely to be younger, be employed, have an anxiety disorder, and have worse scores on PRO measures. 


\section{References}

1. Asher AL, Kerezoudis P, Mummaneni PV, Bisson EF, Glassman SD, Foley KT, et al: Defining the minimum clinically important difference for grade I degenerative lumbar spondylolisthesis: insights from the Quality Outcomes Database. Neurosurg Focus 44(1):E2, 2018

2. Asher AL, McCormick PC, Selden NR, Ghogawala Z, McGirt MJ: The National Neurosurgery Quality and Outcomes Database and NeuroPoint Alliance: rationale, development, and implementation. Neurosurg Focus 34(1):E2, 2013

3. Asher AL, Parker SL, Rolston JD, Selden NR, McGirt MJ: Using clinical registries to improve the quality of neurosurgical care. Neurosurg Clin N Am 26:253-263, ix-x, 2015

4. Austevoll IM, Gjestad R, Grotle M, Solberg T, Brox JI, Hermansen E, et al: Follow-up score, change score or percentage change score for determining clinical important outcome following surgery? An observational study from the Norwegian registry for spine surgery evaluating patient reported outcome measures in lumbar spinal stenosis and lumbar degenerative spondylolisthesis. BMC Musculoskelet Disord 20:31, 2019

5. Bair E, Brownstein NC, Ohrbach R, Greenspan JD, Dubner R, Fillingim RB, et al: Study protocol, sample characteristics, and loss to follow-up: the OPPERA prospective cohort study. J Pain 14 (12 Suppl):T2-T19, 2013

6. Burwell SM: Setting value-based payment goals-HHS efforts to improve U.S. health care. N Engl J Med 372:897899,2015

7. Centers for Medicare \& Medicaid Services (CMS), HHS: Medicare program; hospital inpatient value-based purchasing program. Final rule. Fed Regist 76:26490-26547, 2011

8. Chan AK: Erratum. Laminectomy alone versus fusion for grade 1 lumbar spondylolisthesis in 426 patients from the prospective Quality Outcomes Database. J Neurosurg Spine 30:858-859, 2019

9. Chan AK, Bisson EF, Bydon M, Glassman SD, Foley KT, Potts EA, et al: Obese patients benefit, but do not fare as well as nonobese patients, following lumbar spondylolisthesis surgery: an analysis of the Quality Outcomes Database. Neurosurgery 86:80-87, 2020

10. Chan AK, Bisson EF, Bydon M, Glassman SD, Foley KT, Potts EA, et al: Women fare best following surgery for degenerative lumbar spondylolisthesis: a comparison of the most and least satisfied patients utilizing data from the Quality Outcomes Database. Neurosurg Focus 44(1):E3, 2018

11. Chen EY, Fox BT, Suzo A, Greenberg JA, Campos GM, Garren MJ, et al: One-year surgical outcomes and costs for Medicaid versus non-Medicaid patients undergoing laparoscopic Roux-en-Y gastric bypass: a single-center study. Surg Laparosc Endosc Percutan Tech 26:38-43, 2016

12. Dettori JR: Loss to follow-up. Evid Based Spine Care J 2:7-10, 2011

13. EuroQol Group: EuroQol-a new facility for the measurement of health-related quality of life. Health Policy 16:199208, 1990

14. Fairbank JC, Pynsent PB: The Oswestry Disability Index. Spine (Phila Pa 1976) 25:2940-2952, 2000

15. Gliklich RE, Dreyer NA, Leavy MB: Registry design, in Registries for Evaluating Patient Outcomes: A User's Guide, ed 2. Rockville, MD: Agency for Healthcare Research and Quality, 2014

16. Gluud LL: Bias in clinical intervention research: methodological studies of systematic errors in randomised trials and observational studies. Am J Epidemiol 163:493-501, 2006

17. Hollis S, Campbell F: What is meant by intention to treat analysis? Survey of published randomised controlled trials. BMJ 319:670-674, 1999

18. Hunt JR, White E: Retaining and tracking cohort study members. Epidemiol Rev 20:57-70, 1998
19. Kerezoudis P, Devin CJ, Goncalves S, Alvi MA, Asher AL, Bydon M: The role of clinical registries in health care, in Guillaume DJ, Hunt MA (eds): Quality and Safety in Neurosurgery. London: Academic Press, 2018, pp 53-67

20. Klaiman T, Pracilio V, Kimberly L, Cecil K, Legnini M: Leveraging effective clinical registries to advance medical care quality and transparency. Popul Health Manag 17:127-133, 2014

21. Langley GB, Sheppeard H: The visual analogue scale: its use in pain measurement. Rheumatol Int 5:145-148, 1985

22. Larsson S, Lawyer P, Garellick G, Lindahl B, Lundström M: Use of 13 disease registries in 5 countries demonstrates the potential to use outcome data to improve health care's value. Health Aff (Millwood) 31:220-227, 2012

23. Lee M Jr: Trends in the law: the Patient Protection and Affordable Care Act. Yale J Health Policy Law Ethics 11:1-7, 2011

24. Luckmann R: Evidence-Based Medicine: How to Practice and Teach EBM, 2nd Edition: By David L. Sackett, Sharon E. Straus, W. Scott Richardson, William Rosenberg, and R. Brian Haynes, Churchill Livingstone, 2000. J Intensive Care Med 16:155-156, 2001

25. McGirt MJ, Speroff T, Dittus RS, Harrell FE Jr, Asher AL: The National Neurosurgery Quality and Outcomes Database $\left(\mathrm{N}^{2} \mathrm{QOD}\right)$ : general overview and pilot-year project description. Neurosurg Focus 34(1):E6, 2013

26. Mummaneni PV, Bisson EF, Kerezoudis P, Glassman S, Foley $\mathrm{K}$, Slotkin JR, et al: Minimally invasive versus open fusion for Grade I degenerative lumbar spondylolisthesis: analysis of the Quality Outcomes Database. Neurosurg Focus 43(2):E11, 2017

27. Murray DW, Britton AR, Bulstrode CJ: Loss to follow-up matters. J Bone Joint Surg Br 79:254-257, 1997

28. Neuropoint Alliance: QOD registries. Neuropoint.org (https://www.neuropoint.org/registries/qod/) [Accessed January 17,2020$]$

29. Parker C, Dewey M: Assessing research outcomes by postal questionnaire with telephone follow-up. TOTAL Study Group. Trial of Occupational Therapy and Leisure. Int J Epidemiol 29:1065-1069, 2000

30. Shih W: Problems in dealing with missing data and informative censoring in clinical trials. Curr Control Trials Cardiovasc Med 3:4, 2002

31. Sims AC: Importance of a high tracing-rate in long-term medical follow-up studies. Lancet 2:433-435, 1973

32. Solberg TK, Sørlie A, Sjaavik K, Nygaard ØP, Ingebrigtsen T: Would loss to follow-up bias the outcome evaluation of patients operated for degenerative disorders of the lumbar spine? Acta Orthop 82:56-63, 2011

\section{Disclosures}

Dr. Bisson: consultant for nView, MiRus, and Stryker. Dr. Mummaneni: consultant for Globus, DePuy Synthes, and Stryker; direct stock ownership in Spinicity/ISD; clinical or research support for this study from NREF; support of non-study-related clinical or research effort from ISSG; honoraria from Spineart; and royalties from DePuy Synthes, Thieme Publishers, and Springer Publishers. Dr. Knightly: NPA board member. Dr. Chan: support of non-study-related clinical or research effort from Orthofix. Dr. Glassman: employee of Norton Healthcare; consultant for K2M and Medtronic; patent holder with Medtronic; clinical or research support for this study from NuVasive; royalties from Medtronic; chair of the American Spine Registry; and past president of the Scoliosis Research Society. Dr. Foley: consultant for Medtronic; direct stock ownership in Digital Surgery Systems, Discgenics, DuraStat, LaunchPad Medical, Medtronic, NuVasive, nView Medical, Practical Navigation/Fusion Robotics, SpineWave, TDi, and Triad Life Sciences; patent holder with Medtronic and NuVa- 
sive; board of directors of Digital Surgery Systems, Discgenics, DuraStat, LaunchPad Medical, nView Medical, Practical Navigation/Fusion Robotics, TDi, and Triad Life Sciences; and royalties from Medtronic. Dr. Potts: consultant for and patent holder with Medtronic. Dr. C. Shaffrey: consultant for NuVasive, Medtronic, and SI Bone; direct stock ownership in NuVasive; patent holder with NuVasive, Medtronic, and Zimmer Biomet. Dr. Haid: royalties from Globus Medical, Medtronic, and NuVasive; and shareholder in Globus Medical, NuVasive, Paradigm Spine, SpineWave, and Vertical Health (SpineUniverse). Dr. Fu: consultant for SI Bone, Globus, and Johnson \& Johnson. Dr. Wang: consultant for DePuy Synthes Spine and Stryker; patent holder with DePuy Synthes Spine; ownership in Spineology; and direct stock ownership in ISD and Medical Device Partners. Dr. Park: consultant for Globus and NuVasive; royalties from Globus; and support of nonstudy-related clinical or research effort from DePuy.

\section{Author Contributions}

Conception and design: Bydon, Bisson, Alvi. Acquisition of data: Alvi, Chan. Analysis and interpretation of data: Alvi, Chan.

Drafting the article: Alvi, Chan, Biase. Critically revising the article: Bisson, Alvi, Goyal, Chan, Guan, Biase, Strauss, Glassman, Foley, Slotkin, Potts, M Shaffrey, CI Shaffrey, Haid, Wang, Park, Asher. Reviewed submitted version of manuscript: all authors.
Approved the final version of the manuscript on behalf of all authors: Bydon. Statistical analysis: Alvi, Fu. Administrative/technical/material support: Bydon, Bisson, Mummaneni, Knightly. Study supervision: Bydon, Bisson, Mummaneni, Knightly.

\section{Supplemental Information}

\section{Previous Presentations}

This project was awarded the Kuntz Scholar Award for Top Abstracts at the 35th Annual Meeting of the Section on Disorders of the Spine and Peripheral Nerves, March 14-17, 2019, Miami Beach, Florida.

\section{Correspondence}

Mohamad Bydon: Mayo Clinic, Rochester, MN. bydon. mohamad@mayo.edu. 